\title{
POTENTIALS OF AUGMENTED REALITY IN A BIM BASED BUILDING SUBMISSION PROCESS
}

\author{
SUBMITTED: January 2021
}

REVISED: March 2021

PUBLISHED: July 2021

GUEST EDITORS: Kirti Ruikar, Ketan Kotecha, Sayali Sandbhor, Albert Thomas

DOI: $10.36680 /$ j.itcon.2021.024

\author{
Christian Schranz, Assistant Professor \\ Faculty of Civil Engineering, TU Wien, Vienna, Austria \\ Christian.Schranz@tuwien.ac.at
}

Harald Urban, Ph.D. candidate

Faculty of Civil Engineering, TU Wien, Vienna, Austria

Harald.Urban@tuwien.ac.at

\author{
Alexander Gerger, Research Assistant \\ Faculty of Civil Engineering, TU Wien, Vienna, Austria \\ Alexander.Gerger@tuwien.ac.at
}

SUMMARY: The digital transformation in the construction industry, which is also referred to as Construction 4.0, is gaining impact in recent years. BIM as the central point for model-based planning and communication is at the centre of this development. This paves the way for the implementation of further technologies, such as augmented reality (AR) or artificial intelligence (AI) in the construction process. However, the submission process currently receives little attention in the BIM project cycle, even though it has a significant impact on a building project. There is a huge potential for the application of BIM and AR in the building submission process. BIM allows partly automatic compliance checks to be performed. The BIM model and the results of these checks can be used as basis for the AR model. This paper investigates an application for AR in a BIM submission process. Here we show that especially the plan check process and hearings in the approval process can be improved and sped up by combining BIM and the visualization technology of AR. In this process, AR can support the building authority in checking the compliance with building regulations. Additionally, non-experts involved often have problems grasping the planned building project just based on the technical 2D plans. In this case, AR helps them to visualise the impact of the planned project and allows for better judgement. Use-cases are presented, showing strategies to improve the plan check process and assist the building authority as well as the persons involved, for both experts as well as non-experts. Finally, the requirements, technical implementations, and effects of an AR application for the plan check process are described. An AR-supported plan checking process can vastly improve the presentation of technical content. This leads to better understanding and more transparency for non-experts. Because AR is relatively easy to use, it might become ubiquitous not only to experts, but also to the general public.

KEYWORDS: Building Information Modelling, Augmented Reality, building submission, plan check process, concept.

REFERENCE: Christian Schranz, Harald Urban, Alexander Gerger (2021). Potentials of Augmented Reality in a BIM based building submission process. Journal of Information Technology in Construction (ITcon), Special issue: 'Next Generation ICT - How distant is ubiquitous computing?', Vol. 26, pg. 441-457, DOI: 10.36680/j.itcon.2021.024

COPYRIGHT: (C) 2021 The author(s). This is an open access article distributed under the terms of the Creative Commons Attribution 4.0 International (https://creativecommons.org/licenses/by/4.0/), which permits unrestricted use, distribution, and reproduction in any medium, provided the original work is properly cited. 


\section{INTRODUCTION}

Digital transformation (digitisation, automation, integration) is currently making its way into more and more areas of the industry (Oesterreich and Teuteberg, 2016). This is accompanied by a shift from the traditional projectoriented approach to a process-oriented approach which requires established processes to be fundamentally rethought and optimised (Dallasega et al., 2018). The new technologies make it possible to collect data at all stages of the life cycle. Therefore, digitisation is also advancing more rapidly in the construction industry. This is labelled as Construction 4.0 (Klinc and Turk, 2019; Sawhney et al. 2020) - similar to Industry 4.0. In the construction industry, this development is significantly driven by the use of Building Information Modelling (BIM), especially integrated BIM (iBIM). iBIM is another term for BIM level 3 (Bew and Richards, 2013) or BIM stage 3 (DIN EN ISO 19650-1, 2018). In addition to BIM, various technologies are speeding up this development, these include: BIM, augmented reality (AR), virtual reality (VR), robotics, 3D printing, artificial intelligence (AI) and drones. Some of these technologies are already available (e.g., BIM), however others (e.g., AR, VR) are still in development for general use (Oesterreich und Teuteberg, 2016). Large-scale deployment of all Construction 4.0 technologies (especially AR) is not yet a given, and pilot projects and best practice projects are still being implemented. The construction industry is known for its resistance to change (Mansor, 2010), but as Oesterreich and Teuteberg (2016) state: "Nonetheless, the adoption of the Industry 4.0 concept can help the construction industry to transform into a technology-driven industry and to keep up with other manufacturing sectors in terms of performance improvement."

Construction 4.0 relies not only on the use of individual technologies, but on an increased connectivity and interaction of Construction 4.0 technologies (Rüßmann et al., 2015). BIM (especially iBIM) is one of the core technologies. The BIM model has a great potential (Sanchez et al., 2016; Gerbert et al., 2016). As a starting point for building data and information, these advantages apply not only to the planning phase, but also to the construction phase (Changali et al., 2015) and the operating phase (Sanchez et al., 2016). The BIM model contains geometric as well as alphanumeric information that can be used in all these phases (Borrmann et al., 2018; Sacks et al., 2018). The use of this data allows BIM tools to perform a wide range of simulations and visualizations. These can be building physics simulations, but also simulations of scheduling (4D planning) and cost planning (5D planning) of an entire project (Wang et al., 2014). This applies not only to planning, but also to construction and construction logistics. Corresponding BIM applications have great potential for the future of construction. The BIM model could also help to improve the building quality by a timely identification of potential problems in the BIM model during the design phase (Dallasega et al., 2018). The usage of BIM extends to more areas in the construction industry, e.g., transportation infrastructure (Costin et al., 2018).

Perrier et al. (2020) conclude that the information model is changing more and more into an integrated model (e.g., BIM combined with other technologies). Hence, Construction 4.0 technologies will continue to change all processes of construction project management (including time, personnel, communication, etc.). For these changes to be successful, they need to be accepted by the users of the Construction 4.0 technologies. This is achieved when users perceive the technologies as easy to use and easy to control (Elshafey et al., 2020). Then the users view these technologies as useful and have confidence using them.

\section{1 $A R$ in the construction industry}

In Construction 4.0 the BIM model will be the basis and centre for most other technologies, e.g., AR. Wang et al. (2014) presents that AR and BIM can improve the access to information on the construction site. Urban et al. (2019) describe AR as a good way for improving BIM implementation on construction sites by using headmounted displays. AR is a visualization technique that uses a fixed geographic coordinate system to superimpose virtual 3D models on physical reality (Azuma et al., 2001). The usefulness of AR in the AEC industry is shown in many studies (e.g., Shin and Dunston, 2008; Wang and Love, 2012; Chi et al., 2013; Rankohi and Waugh, 2013; Li et al., 2017; Fenais et al., 2020). The greater availability of web-based wireless technologies can increase the application areas of AR and make AR suitable for all kind of projects (Omar and Nehdi, 2016). Especially with regard to construction safety, $\mathrm{Li}$ et al. (2018) provide a critical review of VR and AR applications and give a summary of achievements and challenges.

Delgado et al. (2020) present a study of the current usage landscape of AR and VR in the AEC industry and singled out six general use-cases: stakeholder engagement, design support, design review, construction support, operations and management, and training. For these use-cases, they list the main benefits and main challenges. This study 
also demonstrates that AR and VR are not ready to be fully adopted in the construction industry and that research and development gaps remain. Urban et al. (2020) show that one of these gaps is the necessity of a construction site-compatible tracking system. The correct tracking of the virtual model is essential for the productive use, and the construction site poses great challenges to the tracking system due to the external conditions.

Although AR is often studied together with VR, in the construction industry AR is preferred over VR since the on-site work of construction requires a mobile visualization technique (Wang et al., 2013): "AR will be the siteextension of BIM concept and approach. AR will maximize the potential of BIM on the construction site, and eventually become a digital toolkit for construction workers." The BIM model is integrated into AR and, then, the building geometry and data can be visualised in the real environment. This assists everyone on the construction site and can help to reduce construction time, cost, and effort (Hou et al., 2013). Zaher et al. (2018) show the potential of a mobile augmented reality application in construction projects. The proposed use of handheld mobile devices offers a cost-effective way to monitor the work progress.

Augmented Reality is especially useful for the inspection of the built construction on the site. Dunston and Shin (2009) described this use-case for the inspection of critical structure or elements. They evaluated AR for the inspection of steel columns (Shin and Dunston, 2009; Shin and Dunston, 2010). Park et al. (2013) present a framework for an automatic inspection by AR and BIM to support the defect management on construction sites. Kwon et al. (2014) adds an AR app to this defect management framework. Mobile AR systems allow easier inspections of concrete and masonry embedment (Olson et al., 2019) and reinforcement (Abbas et al., 2020). AR inspection tools with 3D annotations have proved to be even more effective (Marino, 2021). Generally, an exact tracking of the AR model on the construction site is necessary for an inspection. However, over longer distances most AR tracking systems are still not very accurate (Zhou et al., 2017; Urban et al., 2020).

\subsection{Use of AR for building authorities}

The potential arising from the integrative use of Construction 4.0 technologies has been shown for the construction industry, especially for on-site application. But also governing bodies, like building authorities, should use these technologies to optimize and improve their processes. In Vienna (Austria) alone, around 13,000 applications for building permissions are submitted each year. The broad participation of different departments and partners in the building permit process, combined with the still largely traditional submission of printed plans, leads to a long submission process which can take up to a year. That is why digitisation offers great potential for optimisation, especially in the submission process for building authorities. This already starts with small steps, from the digital building files (mostly pdf submissions) to the fully digital building application or building submissions. The logical next step is the submission of the BIM model. The potential of the digital transformation of the building submission process is already demonstrated by developments in Singapore (Kaneta et al., 2016, Corenet, 2016).

The integration of BIM in the building submission process is the first step, which paves the way for other Construction 4.0 technologies to follow. The authors see great potentials in the usage of Augmented Reality for building authorities. Hence, two research questions arose:

- How can Augmented Reality be implemented to support building authorities during the submission process?

- How can Augmented Reality be implemented to support other persons involved in the submission process, especially non-experts?

Since neighbours of the construction site have special rights in some countries and can prolong the whole submission process, the second question is especially important. During the construction period, building authorities can use AR for inspection of the built construction. This is similar to the inspection use-case for the construction industry. A software like Gamma AR (Gamma Technologies, 2021) or similar could be used. The more challenging task is the one for the plan check process. In this period, the building authority checks the compliance of the submitted building with the building regulations. Hence, an AR tool for the plan check process has to include building regulations for the construction site.

The authors are working on a research project of the City of Vienna to answer the research questions. Several years ago, the City of Vienna started the development of a digital building submission. The EU (Urban Innovative Actions) funded research project "BRISE-Vienna" (UIA, 2019) is developing the building submission even further 
through innovative approaches. In addition to the development of a full openBIM submission process (Krischmann et al., 2020) using IFC files and creating a semi-automatic model checking, Construction 4.0 technologies are to be used. Artificial Intelligence will be employed by another research team to transform legal matters into a digital model. The zoning and development plan in Vienna contains some important building regulations for each construction site in text form (e.g., permitted building height, required shape of the roof). This information will be extracted using AI algorithms to create a reference model, called REM (see Section 3).

The authors have the hypothesis that AR can substantially support all stakeholders involved in the plan check process of the submission and approval process and, hence, work on a concept for a prototype for the use of AR in this process. On the one hand, it will support the building authorities during this process. Therefore, Section 2 will explain the "standard" submission process, followed by the new one using an openBIM model. This will help understanding the presented use-cases of AR during the plan check process. On the other hand, AR supports all persons involved in the submission process. In the current process, these persons get the application plan (2D plan) to see the impact of a new building on their surroundings. Especially for non-experts, these 2D plans are often difficult to understand. In the future, an AR model enriched with the information of important building regulations could be available. This helps them to visualise the impact of the planned project und to participate better in the submission process. This adds "citizen participation" to the general use-case "stakeholder engagement" (Delgado et al., 2020). Augmented Reality seems to have the potential to be the ubiquitous Construction 4.0 technology most recognised by the general public.

\section{CURRENT SITUATION OF THE BUILDING SUBMISSION PROCESS USING VIENNA AS AN EXAMPLE}

The submission process for building projects differs in each country in terms of the procedure, the scope of the technical and legal examination, as well as the rights for objection. In general, with a few exceptions (Kaneta et al., 2016, Corenet, 2016), the submission, review, and examination are carried out on the basis of 2D plans which are available in printed form or as a digital 2D plan (e.g., PDF). Furthermore, in Vienna, the building submission process for building projects requiring a permit is almost exclusively done in paper form. Therefore, the building owner submits his documents (e.g., building plans, powers of attorney, verifications, calculations, survey plan) to the building authority. Figure 1 illustrates the steps of the submission and approval process. After the submission, the building authority validates the completeness of the submitted documents. Then the plan check process starts. The city's building authority then manually examines the submitted documents in cooperation with other specialised departments. These departments check the submitted building projects for compliance with the applicable legal requirements, especially, the Vienna building code. The Vienna building code establishes a link with the zoning and development plan. The zoning and development plan is also a 2D plan. In this plan, the legal requirements for the development of properties (e.g., building alignment, permitted building height, maximum density, type of building) are regulated. During the plan check process, people involved in the proceedings like planners, neighbours, or property owners have the right to check the submitted documents and the opportunity to submit statements (in the statement period). The Vienna building code now includes additional rights which are different from those in many other countries. The aforementioned people also have the opportunity to raise objections. After a certain period of time, the building authority conducts a "hearing in approval process" (hereafter simply called "hearing") to which all the people involved are invited. In this hearing all comments and objections are discussed. In the process steps "Validation", "Statements period", and "Hearing" the planner can be told to consider the objections in his plans and resubmit the building project.

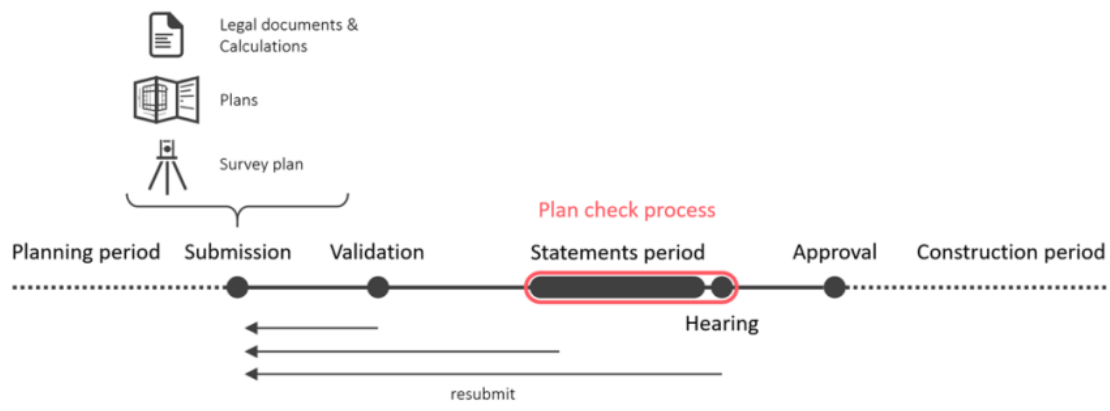

FIG. 1: Steps of the submission and approval process in Vienna. 
For the protection of the interests of neighbours (someone directly affected by the building project) the Vienna building code also provides regulations, which are checked at the very beginning of the submission process. After successfully verifying that all rights of the neighbours are protected, certain groups of persons may view and check the documents. These procedures, rights, and obligations of other persons involved are also regulated in the Vienna building code.

Three groups are distinguished with regard to their rights within the framework of participation in the procedure (e.g., submitting statements). Neighbours are the most relevant group of persons involved in the submission procedure, as they can significantly increase the duration of the procedure. In Vienna, neighbours are defined as those persons whose property either has a common boundary with the property affected by the building project or is located at a certain distance from this property (defined by the Vienna building code). The next group consists of other involved persons, e.g., planners or property owners. Neighbours and other involved persons always have the opportunity to check the submitted documents for all building projects requiring a building permit. They can submit statements (comments and objections) within this framework. If a statement is submitted, the status of the person changes to that of a party (a party has more rights during the submission process). However, the examination of plans and files may only take place within a specified period of time (the statement period). If no statement is submitted during this limited time period, the right of neighbours to check the plans and files and to submit statements expires. This person will then be a member of the last group: a common citizen (without special rights).

The opportunity of examination begins in the submission procedure from the moment of the submission of the building project. The building project is checked by the building authority whether it fulfils all required regulations concerning building technology and building law. If the building authority determines that all requirements are met, the neighbours are notified that they can check the 2D plans and submit written comments and objections by e-mail or letter. The plan check can be done only in person at the building authority's office two days a week. All objections will be examined by the building authority and addressed at the hearing. The date of the hearing is also included in the notification. Hearings are held at the building authority's office or at the construction site itself and are the last opportunity to submit statements. During the hearing, questions and statements arising from the plans are discussed.

The use of plans as a means of communication between technicians is indeed an effective method. However, for non-experts (e.g., neighbours) the language of plans is often difficult to understand. In many cases, this uncertainty leads to a defensive attitude and many misunderstandings or questions. This ties up the resources of the building authority, reduces the speed of the process, and weakens the position of the neighbours. Therefore, one of the five most common reasons for delays in the building submission process is "lack of cooperation from neighbours" (Gerger et al., 2020). This highlights the need to create a transparent, citizen-oriented approach.

\section{OPENBIM SUBMISSION PROCESS AS A BASIS FOR THE USE OF AR}

So far, BIM has played a minor role in the building submission process, with a few exceptions (Kaneta et al., 2016, Corenet, 2016). However, the current submission process presents additional work for BIM planners, since they have to generate conventional 2D plans in a form the building authorities accept out of the BIM model. In the research project "BRISE-Vienna" the City of Vienna intends to develop a complete openBIM submission process. The project focuses on model-based examination using verification software and model-based examinations and hearings using AR. The concept of the openBIM submission process is described in detail in Krischmann et al. (2020). This section deals with the necessary information for model-based examinations of the building authority and the hearings.

A model-based submission process has the advantage that geometric and semantic information from the applicant's model can be checked for legal compliance by software partly in an automatic way (Eastman et al., 2009; Malsane et al., 2015; Armor and Dimyadi, 2021). The basis for the model-based check is the creation of a survey plan in which land, public facilities (e.g., roads, hydrants), building site, alignment lines, neighbouring buildings (e.g., sight distance), and important parameters and provisions of the zoning plan are included. The planner creates a special BIM model in a BIM authoring software based of the information in the survey plan, which is called a building application model (BAM). The model-based submission is developed in openBIM, since the building authority must not dictate the usage of a specific software. The ISO-certified, open Industry Foundation Classes (IFC) standard is the standard for the exchange of information between the participants in openBIM projects and, 
therefore, forms the basis for an openBIM submission process. IFC is a standardised data scheme based on the EXPRESS data modelling language, which is governed by the STEP standard (ISO 10303-11). The BAM is generated from the BIM model available in the architectural authoring software in IFC format and includes all geometric and alphanumeric information agreed on with the planner at that time. Hence, it not a separately managed specialist model. The building authority in Vienna uses level of information need (LOIN) to precisely define the minimum content of the BAM. This includes all the necessary geometric and alphanumeric information so that a semi-automatic check can be performed. The building authority in Vienna requires that the LOIN must partially exceed the current requirements of common Exchange Information Requirements EIR (DIN EN ISO 19650-1), for example (Krischmann et al., 2020):

- $\quad$ The gross floor areas are modelled as 3D objects in order to be able to check maximum buildable areas.

- $\quad$ The nomenclature of room names must be partially specified so that related requirements can be checked against them (e.g., walls surrounding fuel storage rooms must have a fire protection qualification).

- A selection option for stair types is required to check escape route lengths only for relevant stair flights (e.g., differentiation of "main stair" and "secondary stair").

The zoning and development plan contains additional important building regulations for the building potentials of a construction site. These regulations (e.g., building alignment, permitted building height, maximum density, type of building, required shape of roof) are available as lines or text information in the 2D zoning and development plan. In order to check this information with the BAM, another model must be created - the 3D reference model (REM). For this purpose, a survey plan must be created, which includes correctly positioned existing buildings as well as the important information of the zoning and development plan. The survey plan must comply with the specifications of the building authorities with regard to structure, element designation, and information content. After the building authority verifies that the survey plan meets their mandatory specifications, the REM will automatically be generated using the survey plan. This automatic generation is currently developed in the project "BRISE-Vienna". Figure 2 shows the BAM (left), an example of the REM (centre), and the overlay of both models (right). It can be seen like a virtual shell that is put over the BAM in the course of the plan check process. This overlay enables the cross-checking of overlaps, positional correctness, and information details concerning the LOIN.

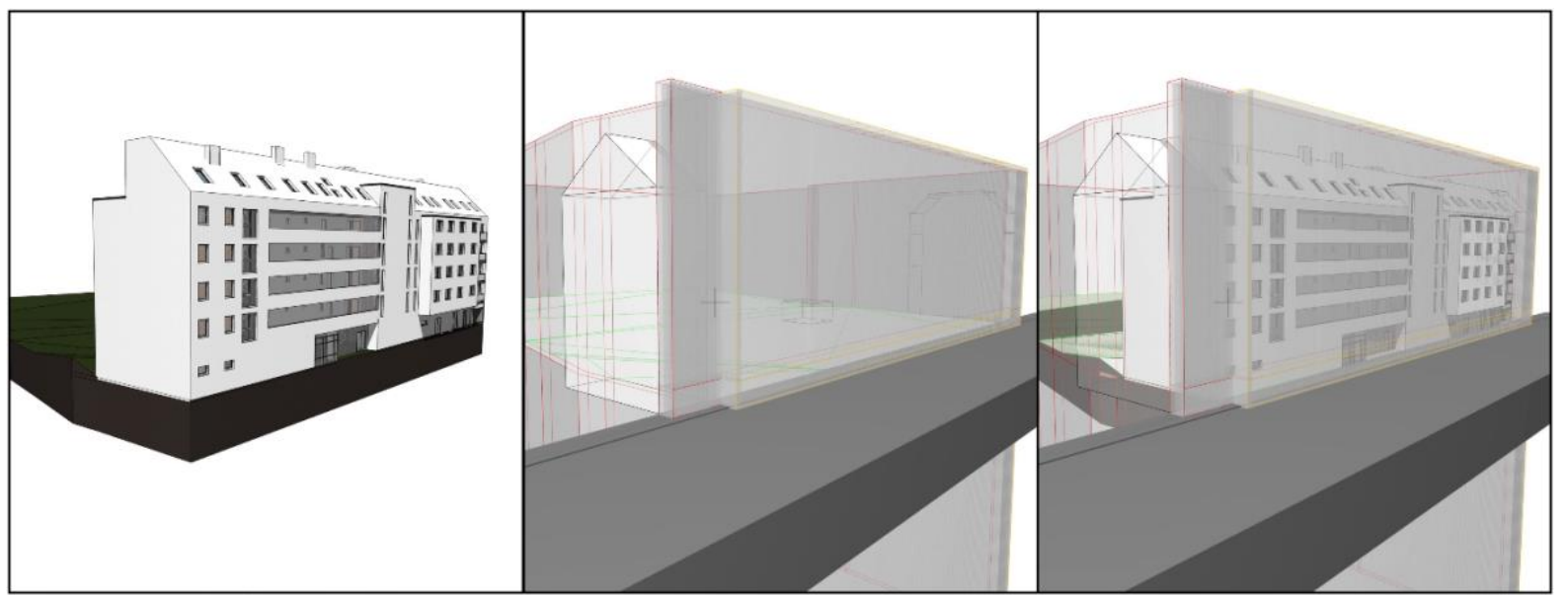

FIG. 2: Building application model BAM (left), reference model REM (centre), and overlay of both models (right).

In addition to the REM, the generation of the application information model (AIM) takes place in the course of the building submission process. The AIM is an IFC file that contains only alphanumeric information. This model includes application-related information and regulations (e.g., parking space regulations), which are not represented in the BAM and REM. These three models are used to perform the model-based checking in the submission process. Depending on the selection of the procedures and certain framework conditions (e.g., status as either new building or existing building, changes in room use), a specific set of checking rules is activated and 
verified. In the research project "BRISE-Vienna" the software Solibri is used. The result is a report in the BIM Collaboration Format (BCF), which is reviewed, edited, and finalised by the authority. After positive review by the building authority, the BAM, REM, and examination results are available as a BCF file for a model-based examination and the hearing with all persons involved.

\section{AUGMENTED REALITY IN THE CONTEXT OF DIGITAL CONSTRUCTION PROJECTS}

The use of digital spatial building models in the openBIM submission process enables the use of AR as a link between authorities and all persons involved. In the research project "BRISE-Vienna" an AR app for digital viewing will be created especially for the plan check process. This AR app shows a spatial representation of the planned construction project with additional information. On-site, this AR model is embedded between the actual neighbouring buildings, whereas in the building authority's office also the digital representation of these neighbouring buildings is included. Visualisations using AR offer great advantages in terms of understandability und usability for both experts and non-experts (Meža et al. 2015). In this case, it helps persons involved to understand the whole project much better. The use of tablets as hardware for AR-supported use-cases also enables the digitisation of the plan check process. Additional explanations, examinations of files, and the ability of digitally submitted statements give the persons involved a better chance to voice their objections.

The implementation of AR in the construction process offers potentials at any stage of the lifecycle (Bademosi and Issa, 2018). In the research project "BRISE-Vienna" the authors particularly focus on AR software development and evaluation in the plan check period during the building submission and approval process. Initially, Gerger at al. (2020) conducted an application and requirements analysis of AR potential for the entire building authority process. The first step was a process analysis of existing procedures. The authors held interviews with all stakeholders. Based on the surveyed status quo, use-cases for the application of AR were defined (Gerger et al., 2020; Schranz, et al., 2020) not only for the actual submission process but also beyond this process. Figure 3 provides an overview of the topics considered (innermost ring), the use-cases identified (middle ring), and the timing in the overall process (thin outermost ring). From the use-case in this figure, three are described in more detail in this article. They are from the areas of plan check process and hearing in approval process and highlighted in more prominent colours: plan checking at the building authority's office, plan checking on-site, and hearing at the building authority's office. The on-site plan checking actually includes two use-cases: one for persons involved in the project and one for the general public. Section 4.1 discusses the provision of the required data and the functionality of the AR app before the individual use-cases are explained in more detail in Sections 4.2 to 4.5.

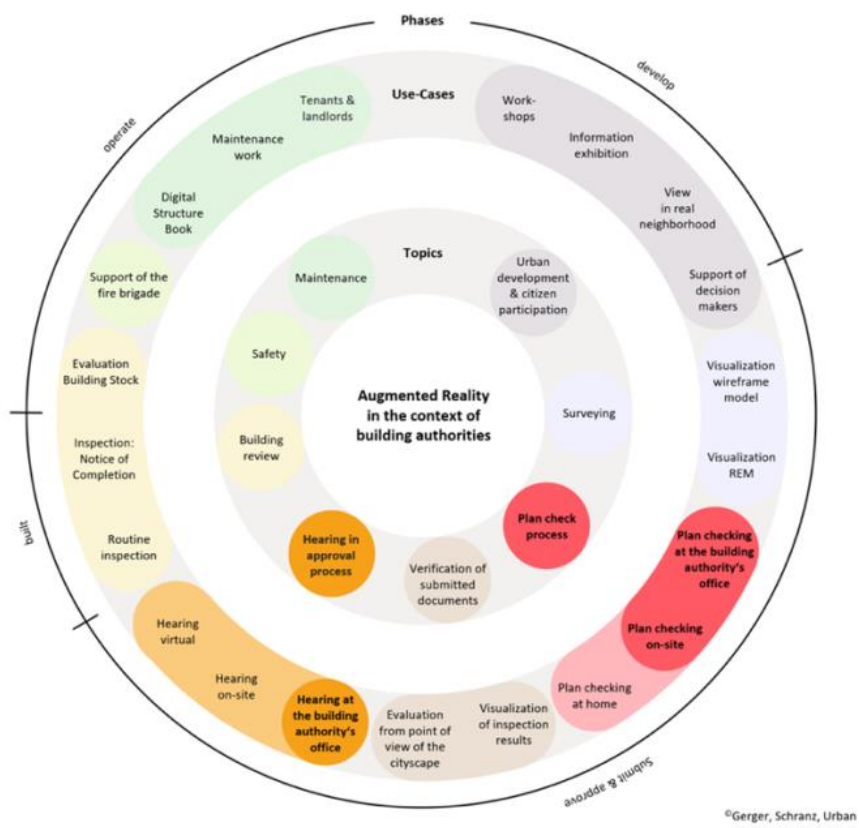

FIG. 3: Overview of all identified AR use-cases suitable for the building authority (modified from Gerger et al., 2020). 
The target group for these use-cases of the AR app includes two main categories: experts (e.g., building authority officials and planners) and non-experts (e.g., neighbours). Therefore, the AR app must include functionalities supporting both, experts and non-experts. The proposed functionalities are:

- Visualisation of the planned building as well as the surrounding buildings,

- $\quad$ all relevant documents (e.g., results of structural analysis, building physics),

- legal information (e.g., permitted building height, distance rules) from the zoning and development plan as well as the building code,

- $\quad$ visualisation whether these legal information are met (if possible), e.g., compliance with the permitted building height,

- additional simulations like a shadow-casting-simulation depending on the date and time,

- $\quad$ glossary of specific (legal and technical) terms which can be called up in graphical form (e.g., an explanation of the building line including representation in the AR model), and

- $\quad$ option to submit statements (comments and objections) including text and photos directly in the AR app.

For this purpose, the geometric (e.g., geometry of the alignment lines) and semantic information (e.g., designation of the line as an alignment line) from the BAM and the REM are used.

\subsection{Data required for the proposed use of $A R$ in the openBIM submission process}

In order to determine the requirements for the software and the necessary information, the entire process must first be defined. Figure 4 shows the process steps required for an AR-supported plan check process at the building authority's office. Steps 01 to 04 are general steps needed to prepare all the information required for the use-cases presented in Sections 4.2 to 4.5. Steps 05 to 10 are part of the AR-assisted plan checking described in Section 4.2. The building authority process begins in Step 01 with the upload of the required building application documents (e.g., BAM, survey plan, structural analysis, expertise). This triggers two parallel processes.

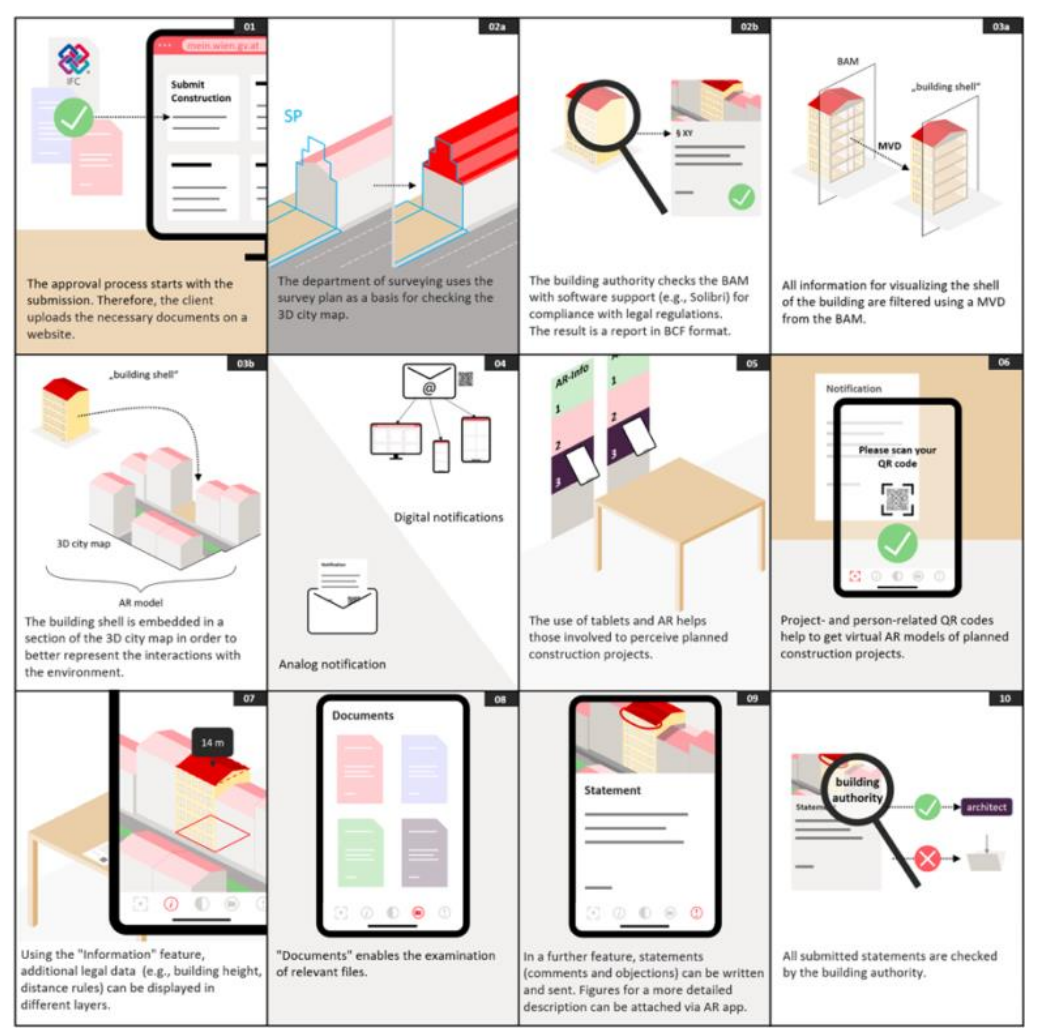

FIG. 4: Process steps required for the plan check process at the building authority. 
The first process (Step 02a) aims to provide a model of the neighbouring buildings so that the planned construction project can be shown including surrounding buildings as part of the plan check process. For this purpose, the survey plan is forwarded to the department of surveying. This survey plan is used to check the if the $3 \mathrm{D}$ city map (City of Vienna, 2020) is up-to-date. This map displays surface information (terrain, building structures, roofs) which originates from terrestrial surveys as well as airborne surveys (ALS - Airborne Laser Scanning). The submitted survey plan are used to update the 3D city map. Figure 5 shows a section of the 3D city map, which can be understood as an abstract 3D model of the city of Vienna. These existing abstract 3D models will be used in the AR app.

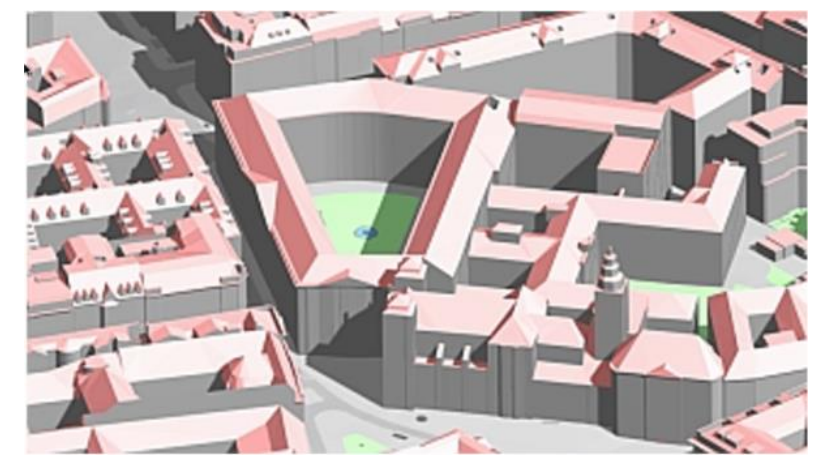

FIG. 5: A section of the 3D city map (City of Vienna, 2020)

For examination purposes, this 3D city map complements the use of AR. Through a combined representation of the submitted building project (BAM) embedded in the abstract surroundings by the 3D city map, citizens can grasp the future situation much better than on the basis of current 2D plan representation. In the latter only a small area of the neighbouring properties is shown. By comparing recorded outlines of neighbouring buildings from the survey plan with existing outlines in the 3D city map, changes since the last surface data collection can be detected and neighbouring buildings can be remodelled if necessary. As a result, a section of the relevant area is exported from the 3D city map for the plan check and forwarded to the building authority. In the long term, this process step (the manual adjustment of 3D surface models compiled at irregular intervals to regularly submitted 2D plans) could be eliminated by introducing a digital as-built 3D plan of the buildings. The ongoing submissions of digital building application models and the merging of these into a georeferenced digital model of Vienna can help the City on their way to an accurate 3D map as an additional benefit of the openBIM building submission. Although the City of Vienna is using the term digital "twin", it is far from a real digital twin as described in Sacks et al. (2020), because of the strict data protection laws in Austria. This digital as-built 3D plan of the buildings could replace or complement the abstracted surface models in the 3D city map and, thus, contribute to an increase in accuracy and timeliness of data.

In the second parallel process (Step 02b in Figure 4) the BAM is checked for compliance with the Vienna building code by the building authority, supported by a verification software as part of the openBIM submission process. The result of the legal and technical check is a report in BCF format. By means of BCF, information about outcome of an examination, its location, viewing direction, components, remarks, users, and time can be transferred. This means that the verification of and compliance with the legal text can also be provided in visual form for persons involved during plan check process (e.g., compliance with the max. building height). The BAM, parts of the REM, and selected test results are visualised in an AR app (Steps 03a and 03b in Figure 4). Besides the visualisation of the construction project, the AR app also serves as a tool to digitise the entire process, including topics like data exchange, communication, and information guidance.

Figures 6 and 7 show the flow of information through the process steps of AR model generation, notification, plan check process with statements period \& check of submitted statements, and hearing in approval process. In this way all aspects of information transfer between building authority, department of surveying, persons involved, file storage, and software components are considered. The aim of the first section "AR model generation" is to prepare all above mentioned models - BAM, REM, 3D city map. There are four main steps in this process:

- $\quad$ The filtering of relevant data from the different partial models using MVDs (e.g., the building shell from the BAM), 
- $\quad$ converting data from IFC format to a format for visualisation using AR and Unity (e.g., JSON, OBJ),

- $\quad$ the merging of all models (BAM, REM, 3D city map) into one AR model, and

- $\quad$ the generation of a project- and person-specific QR code for the retrieval and authentication via an AR app.

The visualisation of the BAM is based on a simplified representation of the building. In doing so, the entire BAM is reduced to the representation of the building's outer shell. This approach is more closely in keeping with the legal requirements in Vienna. Parties can only raise objections in connection with the building exterior, but not with the room layout. Furthermore, the exclusive representation of the building shell protects the building owner's privacy and ensures a better protection of the designer's intellectual property. The reduction of the BAM to the building shell is done by means of Model View Definition (MVD). This can be interpreted as a filter when dealing with IFC models. With this component, all the IFC classes and feature sets that are to be available to people during the plan check process (building exterior, surrounding terrain, outlines of the buildable volume from the REM, and relevant alignment lines) are defined. After the content of the partial models has been prepared for viewing, they must be converted from IFC format into a suitable format (e.g., JSON, OBJ) for visualisation in the AR app.

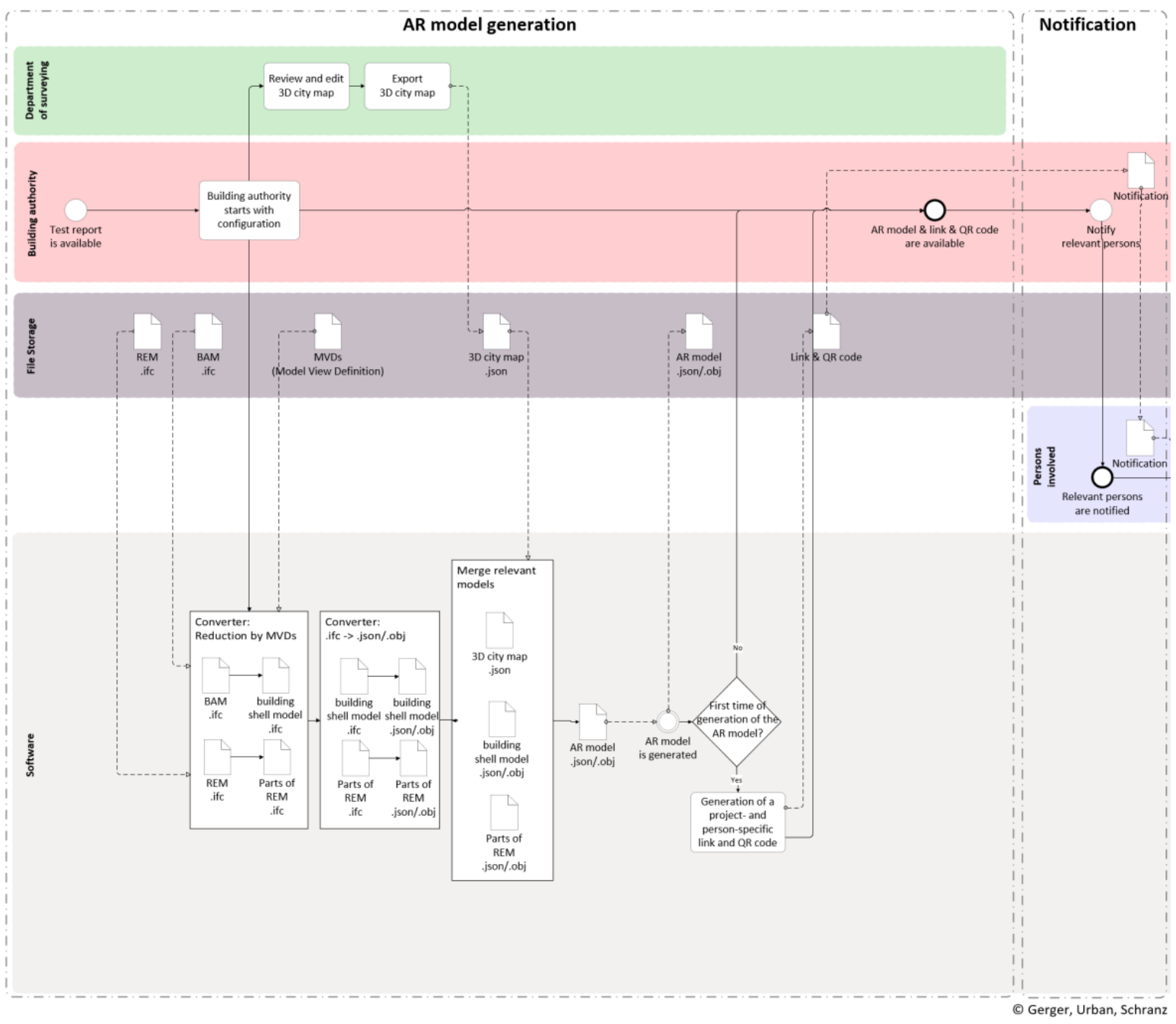

FIG. 6: Flow of information in the phases: AR model generation and notification

Each partial model (BAM, REM, 3D city map) has a project information point (PIP). This contains the coordinates of the origin of the project. By means of the PIP, the individual partial models are referenced in the Gauss-Krüger coordinate system and merged into one AR model. The final step of this process is the creation of the QR code to 
download the AR model. After the content for the AR-supported plan check process has been created, the next section, "Notification", aims to determine all person affected and to inform them officially. The notification comprises the receipt of the building submission, the opportunities to check, and, if applicable, the location and time of the hearing, and includes a person- and project-related QR code. With this code, persons relevant to the procedure can independently download the corresponding AR model at the building authority or on-site and make a plan check. After informing all persons involved, the preparation phase ends and the plan check process follows.

Two options were developed in the research project: plan checking at the building authority's office and plan checking on-site. This is already part of the next section, "Plan check process with statements period \& check of submitted statements", as shown in Figure 7. This section overlaps with the section "Hearing in approval process" because the information flow is the same for both. The information flow is designed as a bi-directional exchange. The textual description in TXT or XML format is attached to a component and, thus, supports the planner according to the openBIM principle. Three types of information are transmitted: the GUID (Globally Unique Identifier) of the relevant component, the textual description of the objection, and the selected view by means of Camera Field of View. All statements submitted must first be converted into BCF format for examination in the verification software. The building authority checks the legal standing of the statements. In addition, the official can process relevant statements (e.g., frequently occurring messages) and they are discussed at the hearing. Subsequently, these statements are converted again into TXT / XML format for use in the AR app.

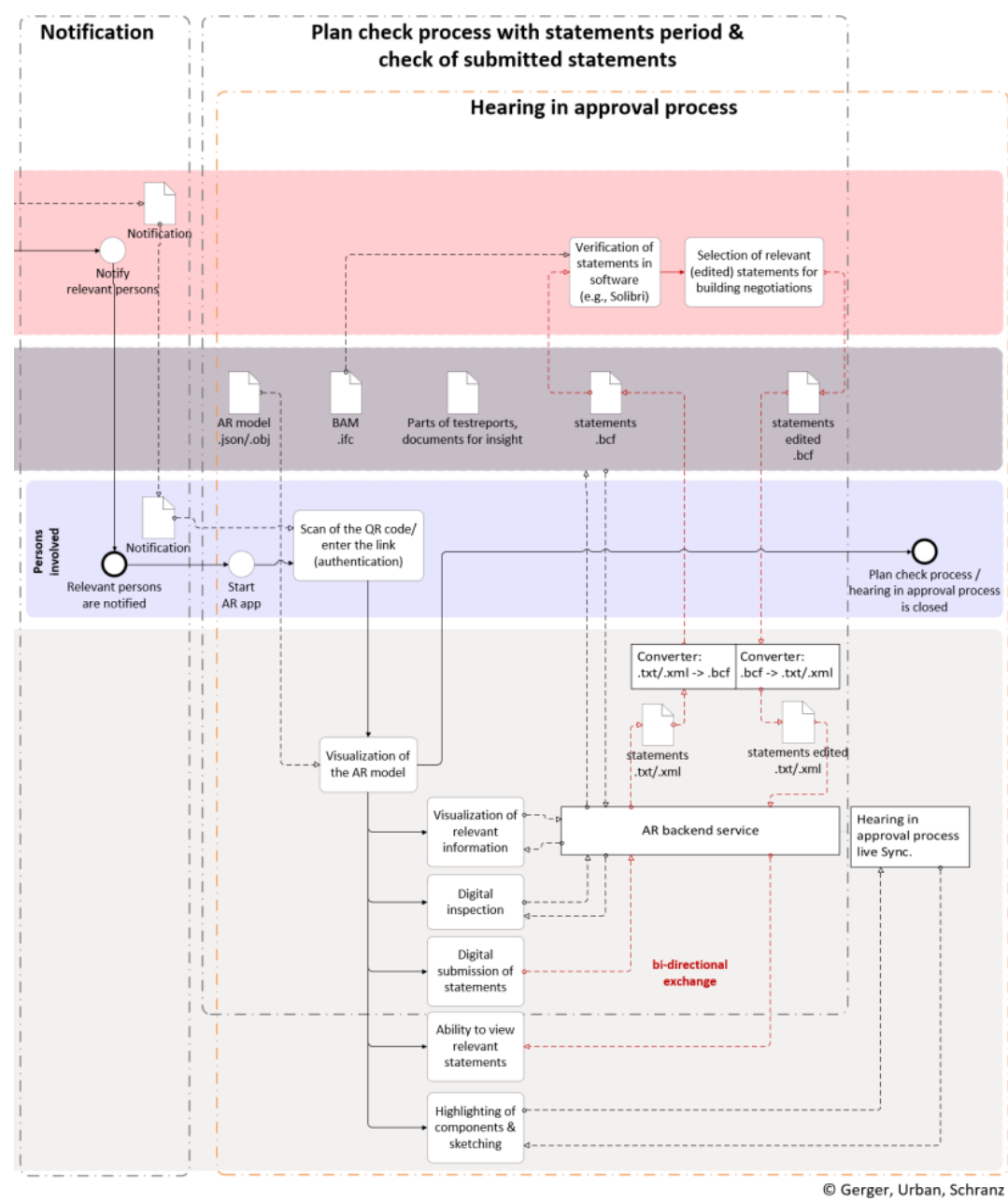

FIG. 7: Flow of information in the phases: notification, plan check process with statements period \& check of submitted statements, and hearing in approval process. 


\subsection{AR-assisted plan checking at the building authority's office}

The existing process is being digitised and modified for plan checking at the building authority's office, in the presence of the authority official. The examination of plans enables the viewing of submitted plans - the examination of files additionally enables the viewing of submission documents (e.g., results of structural analysis or building physics). The main problem is that all plans often have to be explained to the persons involved (who in most cases are not experts) and this requires a great amount of time for the authority official. The use of AR gives participants a lot more freedom and reduces the workload the building authority (Kumaran et al., 2007).

Steps 05 to 10 in Figure 4 show the future situation. There will be a dedicated AR area at the Vienna's building authority's office providing tablets with AR software. The building project in question is downloaded by scanning the QR code or entering the link from the notification. The building shell of the submitted construction project is now visualised in the context of the neighbouring buildings from the $3 \mathrm{D}$ city map as a spatial model above a reference plane (e.g., a table). The AR app uses feature recognition via camera image (e.g., the QR code for downloading the AR model can serve as a feature). This camera-based method is one of the most common tracking systems used for mobile devices (Bostanci et al., 2013) The representation as a spatial model including neighbouring buildings considerably supports all persons involved in grasping the situation. The retrieval of model information and documents is done via AR backend service. Currently, the examination of the submitted documents can only take place in the presence of the authority official at specific times. The plan checking with $\mathrm{AR}$ is intended to assist persons involved to the extent that the help of an authority official is no longer necessary. This relieves both sides: questions addressed to the authority official are first filtered and those involved can view the building project without time restrictions. At the end of the plan checking, statements can be submitted via the AR app. If a person suspects that their rights have been violated, an objection can be formulated digitally on the spot. The submitted statement can only be viewed by the author, the building authority, and persons involved if requested.

\subsection{AR-assisted plan checking on the construction site}

The use of AR enables a completely new form of visualisation as an alternative to plan checking at the building authority's office. With the help of the AR app, the planned construction project can be visualised at the future construction site between the actual neighbouring buildings (see Figure 8). This form of representation of the planned construction project in correct proportion in order to the neighbouring buildings makes it easier for all persons involved to grasp the impact the new building has on its surroundings. The procedure is very similar to that at the building authority's office with the additional process step of positioning.

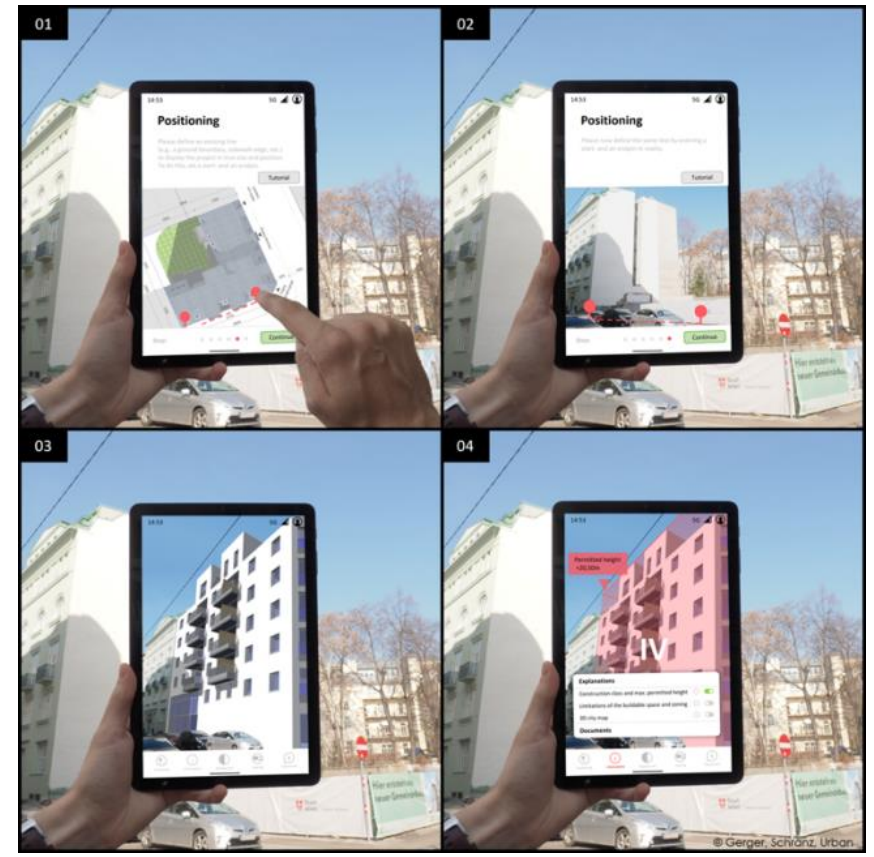

FIG. 8: Conceptual representation of the positioning process. 
After the corresponding AR model has been downloaded via QR code or link, the model still has to be placed in the correct position and with the correct size. In the proposed AR app, the system of vector-based positioning is used for this purpose. First, a top view of the building project and the construction site including boundaries and neighbouring buildings is displayed on the tablet. In this view, a reference vector is defined by specifying start and end of this vector. For example, a base boundary or wall edge of a neighbouring building can serve as a reference vector. In the second step, the user switches to the camera image. The same element must now be defined as a comparison vector. This comparison vector is determined by positioning a start- and an endpin in the environment. By comparing the two vectors in terms of spatial position and length, the AR model is correctly positioned and scaled. The AR model now comes close to reality in the camera image of the tablet or smartphone app. This process is conceptually illustrated in Figure 8.

This use-case offers the big advantage that the plan checking can be done right on the future construction site at any time, independent of the opening hours of the building authority. Hence, the persons involved have a visualisation of the planned building as well as all the needed legal information (e.g., permitted building height). They can make statements via the app, if necessary. Even if the following hearing in approval process is held only at the building authority's office, the persons involved already have a better impression of the building project and the construction site.

\subsection{Hearing in approval process}

In standard procedure, the hearing is the last opportunity for the parties to express their objections to the construction project. In the past, it was held at the construction site in question, but now the building authority's office is preferable, which has both, advantages and disadvantages. On the one hand, travel time for the officials of the building authority is reduced. But on the other hand, there is a loss in the perception of the effects of the construction project on the surroundings for those involved. In the future, the use of AR during hearings at the building authority's office should compensate for this disadvantage.

Each participant at the hearing is provided with a tablet with appropriate AR software. The AR model can be downloaded by means of a QR code or link included in the notification. Each participant can view the visualisation of the building project including the neighbouring buildings (by means of the 3D city map) from their personal perspective. At the beginning, the building project is introduced by the building authority official. The tablets are synchronised live (see Figure 7) for a better support of the explanations. This allows the building authority official to select, highlight, and supplement individual components with spatial sketches, which are displayed to all participants on their devices. All statements, that have been classified as relevant by the authority official, can now be called up via the AR app and discussed between all participants.

\subsection{Public plan checking}

The concept of decentralised on-site plan checking has the potential to further strengthen transparency of all construction activities in the future. The difference between persons involved and common citizens, as laid down in the Vienna building code, is quite arbitrary. The participation of common citizens is, by law, currently only allowed in the context of a public notice for building projects with more than 100 persons involved. In the sense of strengthening citizen participation, the lower threshold for the inclusion of citizens could be adapted in the future. In the case of construction projects submitted by a public client (e.g., schools, cultural facilities) as well as in the case of private construction projects (after the builder has given his consent), it could be made possible for citizens to check the plans. For projects in the public interest, the option of citizen participation in the design phase could be taken into consideration (Boenisch et al., 2017). However, if citizens should generally be given the opportunity to examine planned construction projects, a new concept of notification and access to information is needed because regular on-site plan checking by persons involved would no longer be sufficient. Contrary to the approach with personalised access codes, a two-stage concept could apply here. The first level is a publicly accessible project-related QR code for downloading the AR model for "plan viewing". This level would then be available to all citizens, but without the possibility of raising objections via statements. File examination will continue to be reserved for persons involved, and objections would be reserved for the parties concerned. This second level would only be available after successful authentication in the AR app by smartphone signature. 


\section{CONCLUSION}

Construction 4.0, in particular BIM, has a significant impact on the processes in the construction industry. The building authorities as part of the life cycle of a building are also massively influenced by this. A complete digital transformation of the construction industry is only possible with the involvement of the building authorities. This paper shows new opportunities for building authorities, which arise from the development and spread of openBIM and AR. The combination of both technologies in the plan check process of the submission process enables a more comprehensible representation of content for persons not familiar with the subject. Instead of a technical 2D plan, the content is presented as a spatial 3D model. The interaction happens now through the model-based AR application, and not only through written notes, email, or letter. Augmented Reality will be ubiquitous in the future. This is obvious from the application and requirements analysis carried out. The concept of the AR tool for the plan check process of building applications and hearing are already being studied in the research project "BRISEVienna". The presented concept only works for a submission process as presented in Figure 1 and can only unfold its potential if all the defined documents are uploaded. Otherwise, the AR tool has to be adapted.

An AR-supported plan checking vastly improves the presentation of the technical content. An on-site plan checking also increases the non-expert citizen's understanding of the interaction of the planned project with the real environment. This leads to more participation and transparency for citizens. Model-based communication and the possibility of including explanations reduce the workload of the building authority during the plan check process and, thus, speeds up the process. Joint discussion and interaction via an AR model during hearings also improve the communication between participants and building authorities. Smartphone and tablets enable the implementation for a broad group of people. As a next step, the concept shall lead to a prototype which will be tested with all stakeholders involved.

In the future, AR will be used in a lot of different scenarios (see the use-cases in Figure 3). The use-cases presented in Figure 3 concerning the operational phase are recommended for future research. The use of AR in official procedures will not be limited to smartphones or tablets. In addition, the use of head-mounted displays will become more widespread. This will be especially useful in areas where the authorities carry out on-site building inspections. AR can help them to find their way around on many different construction sites very quickly and recognise differences in advance.

\section{REFERENCES}

Abbas A., Seo J., and Kim M. (2020). Impact of Mobile Augmented Reality System on Cognitive Behavior and Performance during Rebar Inspection Tasks. Journal of Computing in Civil Engineering, Vol. 34, No. 6, 112-121. DOI: 10.1061/(ASCE)CP.1943-5487.0000931

Armor R. and Dimyadi J. (2021). The promise of automated compliance checking. Developments in the Built Environment, Vol. 5, 100039. DOI: 10.1016/j.dibe.2020.100039

Azuma R., Baillot Y., Behringer R., Feiner S., Julier S. and MacIntyre B. (2001). Recent advances in augmented reality. IEEE computer graphics and applications, Vol. 21, No. 6, 34-47. DOI: 10.1109/38.963459

Bademosi F. and Issa R. (2019). Implementation of Augmented Reality throughout the lifecycle of construction projects. In: Mutis I. and Hartmann T. (Eds.): Advances in Informatics and Computing in Civil and Construction Engineering. Springer International Publishing AG, Cham. DOI: 10.1007/978-3-030-002206

Bew M. and Richards M. (2011). BIM maturity model, strategy paper for the government construction client group. Department of Business, Innovation and Skills, London, UK. Online: https://www.cdbb.cam.ac.uk/Resources/ResoucePublications/BISBIMstrategyReport. pdf (Accessed: 12.01.2021)

Boenisch L.-E., Brede A.-K. and Fasching I. (2017). Applied Games. WSP Finland.

Borrmann A., König M., Koch, C. and Beetz J. (Eds.) (2018). Building Information Modeling: Technology Foundations and Industry Practice. Springer International Publishing AG, Cham, DOI: 10.1007/978-3-31992862-3 
Bostanci E., Kanwal N., Ehsan S. and Clark A.F. (2013). User tracking methods for augmented reality. International Journal of Computer Theory and Engineering, Vol. 5, No. 1, 93-98. DOI: 10.7763/IJCTE.2013.V5.654

Changali S., Mohammad M. and van Nieuwland M. (2015). The construction productivity imperative. McKinsey \& Company. Online: www.mckinsey.com/industries/capital-projects-and-infrastructure/ourinspections/the-construction-procuctivity-imperative (Accessed: 15.04.2020)

Chi H.L., Kang S.C. and Wang X. (2013). Research trends and opportunities of augmented reality applications in architecture, engineering, and construction. Automation in Construction, Vol. 33, 116-122. DOI: 10.1016/j.autcon.2012.12.017

City of Vienna (2020). Geo data of the department of surveying (in German). Online: https://www.wien.gv.at/stadtentwicklung/stadtvermessung/geodaten/ (Accessed: 12.01.2021)

Corenet (2016). Building Information Modeling (BIM) e-Submission. Singapore Government. Online: https://www.corenet.gov.sg/general/building-information-modeling-(bim)-e-submission.aspx (Accessed: 10.01.2021)

Costin A., Adibfar A., Hu H. and Chen S.S. (2018). Building Information Modeling (BIM) for transportation infrastructure - Literature review, applications, challenges, and recommendations. Automation in Construction, Vol. 94, 257-281. DOI: 10.1016/j.autcon.2018.07.001

Dallasega P., Rauch E. and Linder C. (2018). Industry 4.0 as an enabler of proximity for construction supply chains: A systematic literature review. Computers in Industry, Vol. 99, 205-225. DOI: 10.1016/j.compind.2018.03.039

Delgado J.M.D., Oyedele L., Demian P. and Beach T. (2020). A research agenda for augmented and virtual reality in architecture, engineering and construction. Advanced Engineering Informatics, Vol. 45, 101-122, DOI: 10.1016/j.aei.2020.101122

DIN EN ISO 19650-1:2018 (2018). Organization and digitization of information about buildings and civil engineering works, including building information modelling (BIM) - Information management using building information modelling - Part 1: Concepts and principles; German version. DIN, Berlin

Dunston P.S. and Shin D.H. (2009). Key areas and issues for augmented reality applications on construction sites. In: Wang X. and Schabel M.A.. (Eds.): Mixed Reality in Architecture, Design \& Construction. Springer International Publishing AG, Cham. 157-170. DOI: 10.1007/978-1-4020-9088-2

Eastman C., Lee J.-m., Jeong Y.-s. and Lee J.-k. (2009). Automatic rule-based checking of building designs. Automation in Construction, Vol. 18, 1011-1033. DOI: 10.1016/j.autcon.2009.07.002

Elshafey A., Saar C.C., Aminudin E.B., Gheisari M. and Usmani A. (2020). Technology acceptance model for Augmented Reality and Building Information Modeling integration in the construction industry. Journal of Information Technology in Construction, Vol. 25, 161-172, DOI: 10.36680/j.itcon.2020.010

Fenais A.S., Ariaratnam S.T., Ayer S.K. and Smilovsky N. (2020). A review of augmented reality applied to underground construction. Journal of Information Technology in Construction, Vol. 25, 308-324, DOI: 10.36680/j.itcon.2020.018

Gamma Technologies (2021). Gamma AR - AR app for construction. Online: https://gamma-ar.com (Accessed: 15.01.2021)

Gerbert P., Castagnino S., Rothballer C., Renz A. and Filitz R. (2016). Digital in engineering and construction: The transformative power of building information modeling. The Boston Consulting Group, Inc.

Gerger A., Schranz C. and Urban H. (2020). Neue Möglichkeiten durch den Einsatz von Augmented Reality im Kontext digitaler Bauvorhaben (New possibilities through the use of augmented reality in the context of digital construction projects, in German). Research report. BRISE-Vienna, TU Wien

Hou L., Wang X. and Truijens M. (2013). Using augmented reality to facilitate piping assembly: an experimentbased evaluation. Journal of Computing in Civil Engineering, Vol. 29, No. 1, 05014007. DOI: 10.1061/(ASCE)CP.1943-5487.0000344 
ISO 10303-11:2004 (2004). Industrial automation systems and integration - Product data representation and exchange - Part 11: Description methods: The EXPRESS language reference manual. CEN, Brussels

Kaneta T., Furusaka S., Tamura A. and Deng S. (2016). Overview of BIM Implementation in Singapore and Japan. Journal of Civil Engineering and Architecture, Vol. 10, 1305-1312, DOI: 10.17265/19347359/2016.12.001

Klinc R. and Turk Ž. (2019). Construction 4.0 - digital transformation of one of the oldest industries. Economic and Business Review, Vol. 21, No. 3, 393-410

Krischmann T., Urban H. and Schranz C. (2020). Entwicklung eines openBIM-Bewilligungsverfahrens (Development of an openBIM submission process, in German). Bauingenieur, Vol. 95, No. 9, 335-344

Kumaran G. S., Santhi K. R. and Anand P. M. R. (2007). Impact of Augmented Reality (AR) in Civil Engineering. Advanced Materials Research, Vols. 18-19, 63-68. DOI: 10.4028/www.scientific.net/AMR.18-19.63

Kwon O.-S., Park C.-S., and Lim C.-R. (2014). A defect management system for reinforced concrete work utilizing BIM, image-matching and augmented reality. Automation in Construction, Vol. 46, 74-81. DOI: 10.1016/j.autcon.2014.05.005

Li W., Nee A.Y.C., and Ong S.K. (2017). A state-of-the-art review of augmented reality in engineering analysis and simulation. Multimodal Technologies and Interaction, Vol. 1, No. 3, 17. DOI: 10.3390/mti1030017

Li X., Yi W., Chi H.-L., Wang X. and Chan A.P.C. (2018). A critical review of virtual and augmented reality (VR/AR) applications in construction safety. Automation in Construction, Vol. 86, 150-162. DOI: 10.1016/j.autcon.2017.11.003

Malsane S., Matthews J., Lockley S., Love P.E.D. and Greenwood D. (2015). Development of an object model for automated compliance checking. Automation in Construction, Vol. 49, 51-58. DOI: 10.1016/j.autcon.2014.10.004

Marino E., Barbieri L., Colacino B., Fleri A.K. and Bruno F. (2021). An augmented reality inspection tool to support workers in Industry 4.0 environments. Computers in Industry, Vol. 127, 103412. DOI: 10.1016/j.compind.2021.103412

Meža S., Turk Ž. and Dolenc M. (2015). Measuring the potential of augmented reality in civil engineering. Advances in Engineering Software, Vol. 90, 1-10. DOI: 10.1016/j.advengsoft.2015.06.005

Oesterreich T.D. and Teuteberg F. (2016). Understanding the implications of digitisation and automation in the context of Industry 4.0: A triangulation approach and elements of a research agenda for the construction industry. Computers in Industry, Vol. 83, 121-139. DOI: 10.1016/j.compind.2016.09.006

Olson D., Kim J. and Taylor J.M. (2012). Using augmented reality for masonry and concrete embed coordination. Proceedings of the Creative Construction Conference 2019, Budapest, Hungary, 906-913. DOI: 10.3311/CCC2019-125

Omar T. and Nehdi M.L. (2016). Data acquisition technologies for construction progress tracking. Automation in Construction, Vol. 70, 143-155. DOI: 10.1016/j.autcon.2016.06.016

Park C.-S., Lee D.-Y., Kwon O.-S. and Wang X. (2013). A framework for proactive construction defect management using BIM, augmented reality and ontology-based data collection template. Automation in Construction, Vol. 33, 61-71. DOI: 10.1016/j.autcon.2012.09.010

Perrier N., Bled A., Bourgault M., Cousin N., Danjou C., Pellerin R. and Roland, T. (2020). Construction 4.0: a survey of research trends. Journal of Information Technology in Construction, Vol. 25, 416-437, DOI: 10.36680/j.itcon.2020.024

Rankohi S. and Waugh L. (2013). Review and analysis of augmented reality literature for construction industry. Visualization in Engineering, Vol. 1, No. 9, 1-18. DOI:10.1186/2213-7459-1-9

Rüßmann M., Lorenz M., Gerbert P., Waldner M., Justus J., Engel P. and Harnisch M. (2015). Industry 4.0: the future of productivity and growth in manufacturing industries. Boston Consulting Group, 9 (191), 54-89

Sacks R., Brilakis I., Pikas E., Xie H.S. and Girolami M. (2020). Construction with digital twin information systems. Data-Centric Engineering, Vol. 1, e14-1-e14-26. DOI: 10.1017/dce.2020.16 
Sacks R., Eastman C.M., Lee G. and Teicholz P. (2018). BIM handbook: A guide to building information modeling for owners, designers, engineers, contractors and facility managers. John Wiley \& Sons. DOI: $10.1002 / 9781119287568$

Sanchez A., Hampson K. and Vaux S. (2016): Delivering Value with BIM: A Whole-of-Life Approach. Routledge, London

Sawhney A., Riley M. and Irizarry J. (Eds.) (2020). Construction 4.0 - an innovation platform for the built environment. Routledge, London. DOI: 10.1201/9780429398100

Schranz C., Gerger A. and Urban, H. (2020): Augmented Reality im Bauwesen: Teil 1 - Anwendungs- und Anforderungsanalyse (Augmented reality in civil engineering: part 1 - use-case and requirement analysis, in German). Bauingenieur, Vol. 95, No. 10, 379-388

Shin D.H. and Dunston P.S. (2008). Identification of application areas for Augmented Reality in industrial construction based on technology suitability. Automation in Construction, Vol. 17, 882-894. DOI: 10.1016/j.autcon.2008.02.012

Shin D.H. and Dunston P.S. (2009). Evaluation of Augmented Reality in steel column inspection. Automation in Construction, Vol. 18, 118-129. DOI: 10.1016/j.autcon.2008.05.007

Shin D.H. and Dunston P.S. (2010). Technology development needs for advancing Augmented Reality-based inspection. Automation in Construction, Vol. 19, 169-182. DOI: 10.1016/j.autcon.2009.11.001

UIA (EU) - Urban Innovative Actions (2019). BRISE-Vienna - Building Regulations Information for Submission Envolvement. Online: https://www.uia-initiative.eu/en/uia-cities/vienna-call4

Urban H., Schranz C. and Gerger A. (2019). BIM auf Baustellen mit Augmented Reality (BIM on the construction site with Augmented Reality, in German). Bauaktuell, Vo. 10, No. 5, 192-196

Urban H., Irschik T., Schranz C. and Schönauer C. (2020): Augmented Reality im Bauwesen: Teil 2 Baustellentaugliches Trackingsystem (Augmented reality in civil engineering: part 2 - site-compatible tracking system, in German). Bauingenieur, Vol. 95, No. 12, 501-508

Wang X. and Love P.E.D. (2012). BIM + AR: Onsite information sharing and communication via advanced visualization. Proceedings of the 2012 IEEE $16^{\text {th }}$ International Conference on Computer Supported Work in Design, 850-855

Wang X., Kim M.J., Love P.E., and Kang S.C. (2013). Augmented Reality in built environment: Classification and implications for future research. Automation in construction, Vol. 32, 1-13. DOI: 10.1016/j.autcon.2012.11.021

Wang X., Truijens M., Hou L., Wang Y. and Zhou Y. (2014). Integrating Augmented Reality with Building Information Modeling: Onsite construction process controlling for liquefied natural gas industry. Automation in Construction, Vol. 40, 96-105. DOI: 10.1016/j.autcon.2013.12.003

Wang X., Yung P., Luo H., and Truijens M. (2014). An innovative method for project control in LNG project through 5D CAD: A case study. Automation in Construction, Vol. 45, 126-135. DOI: 10.1016/j.autcon.2014.05.011

Zaher M., Greenwood D., and Marzouk M. (2018). Mobile augmented reality applications for construction projects. Construction Innovation, Vol. 18, No. 2, 152-166. DOI: 10.1108/CI-02-2017-0013

Zhou Y., Luo H., and Yang Y. (2017). Implementation of augmented reality for segment displacement inspection during tunneling construction. Automation in Construction, Vol. 82, 112-121. DOI: 10.1016/j.autcon.2017.02.007 